\title{
The Corporate Governance and the
}

\section{Distorted Accounting Information}

\author{
Qiufei Wang \\ School of Management, Shenyang Jianzhu University, Shenyang 110004, China \\ Tel: 86-24-2424-3733Ｅ-mail: wangqiufei@126.com
}

\begin{abstract}
Distorted accounting information of the public company becomes the main element restricting our country's economic development. Hence, how to improve accounting information quality becomes a hot topic. This study in brief analyzes some factors, which affect accounting information quality from the direction of corporate governance. Moreover it gives out several different mathematical models and proposes a base train of administering thought, in order to establish a few foundations for research on the distorted accounting information problem.
\end{abstract}

Keywords: Corporate governance, The Distorted accounting information

\section{Introduction}

The distorted accounting information is the "Chronic illness" of securities markets. Because it endangers government Marco-control, disturbs tax revenue and does harm to functioning of optimizing capital resource disposal, many governments attempt to resole this problem. Yet even to this day, varieties of events about distorted accounting information still disturb the whole world. For example "Enron" in United States, and "Yingguanxia"and "lantian" in China. This study concludes that the reason that research and governance on distorted accounting information cannot acquire breakthrough is that it neglects the root of this question. Principal-agent relationship lead to distorted accounting information, so method of only depending on accounting standards and accounting institution is not the most effective way to settle problems.

Corporate governance is an arrangement of law, culture, usual practice and systems, which are use for harmonizing and controlling the relationship and action between every participant. So the most fundamental problem, which will be resolved, is the action of the agent problem. For this reason, it is emergence to benefit conflict between "principal" and "agent" and asymmetric information. All of those evoke distorted accounting information Reports published by COSO, on the basis of the research, which involve 200 public companies with financial report malpractice from 2003 to 1007 , demonstrates that $72 \%$ of the cases are related to CEO, $43 \%$ are related to CFO; $25 \%$ of corporations did not set up the audit commission. The study research specimen included 50 public companies with financial malpractices from 1994 to 2000 ,according to punishments of CSRC, and demonstrates that there are $79 \%$ case related to distorted accounting information and among those is $79 \%$ cases related to directors and managers. (Figure 1)

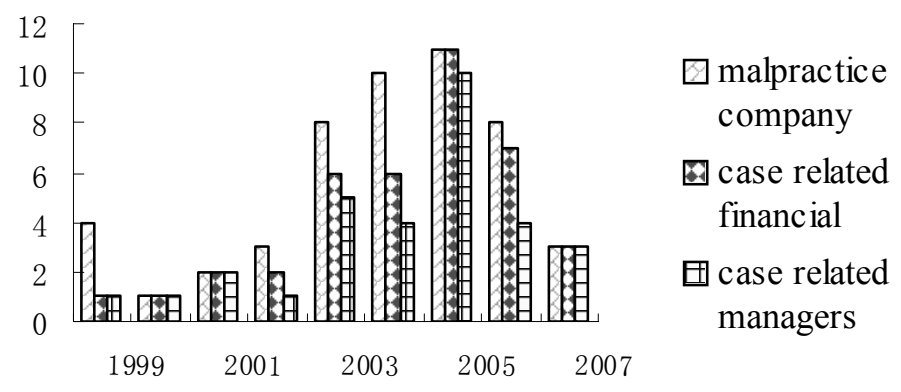

Figue 1. Financial Affairs Malpractices Corporation

In view of the above, we think the reason that induces the distorted accounting information is defects in corporate governance patterns. Because of those defects, some mechanisms cannot supervise and penalize the action. So accounting information cannot be creditable. This study in brief analyzes some factors, which affect accounting information quality from the direction of corporate governance. Moreover it gives out several different instances that directly cause accounting information distort. On this basis, this study designs a mathematical model and proposes a 
base train of administering thought, in order to establish a few foundations for research on the distorted accounting information problem.

\section{Ownership structure and distorted accounting information}

Generally speaking, ownership structure contains two implications: fistly, varied percent possessed by different stockholders; secondly, owner ship structure concentration degree. It is the significant component and the ownership base of corporate governance. Rational ownership structure decides if the basis function by which corporate governance ensures the credible financial report can work well. Stockholders as owners of capital have to make contacts with managers according to the accounting information, and achieve maximum the capital profit. Hence the stockholder is the demander of accounting information. Yet stockholders, with distinct proportion, have different demands. We consider that large stockholders are indeed the accounting information demanders. In this group, the relation ship between economic benefit and accounting information is more important than others, so they possess more power to govern and control quality of the accounting information. Foe example, the person who first discovered "Enron" case was the financial analyst in the investment organization. Rational ownership structure produces accounting information demanders and decreases instances of distorted accounting information.

Through the ownership structure research on the public company with financial report malpractice actions, we discover that there are two distinguishing feature in those companies: first the proportion of circulative stock is to low, and second the first stockholder are nation and "legal person", with the highest proportion being 51\%(Figure 2). In Japan banks are the most important stockholders, with centralized ownership structure being only possess $15 \%$ ( Figure 3 ). Government and manager department as stockholders of national stock and owners of property rights are not able to ask for the remainder, so it is norlt enough impetus for them to supervise and evaluate the manager. So "insider control" becomes an important problem in China. In order to attain to control, an insider must use the distorted accounting information. So this kind of unrightfully ownership becomes the source of distorted accounting information.

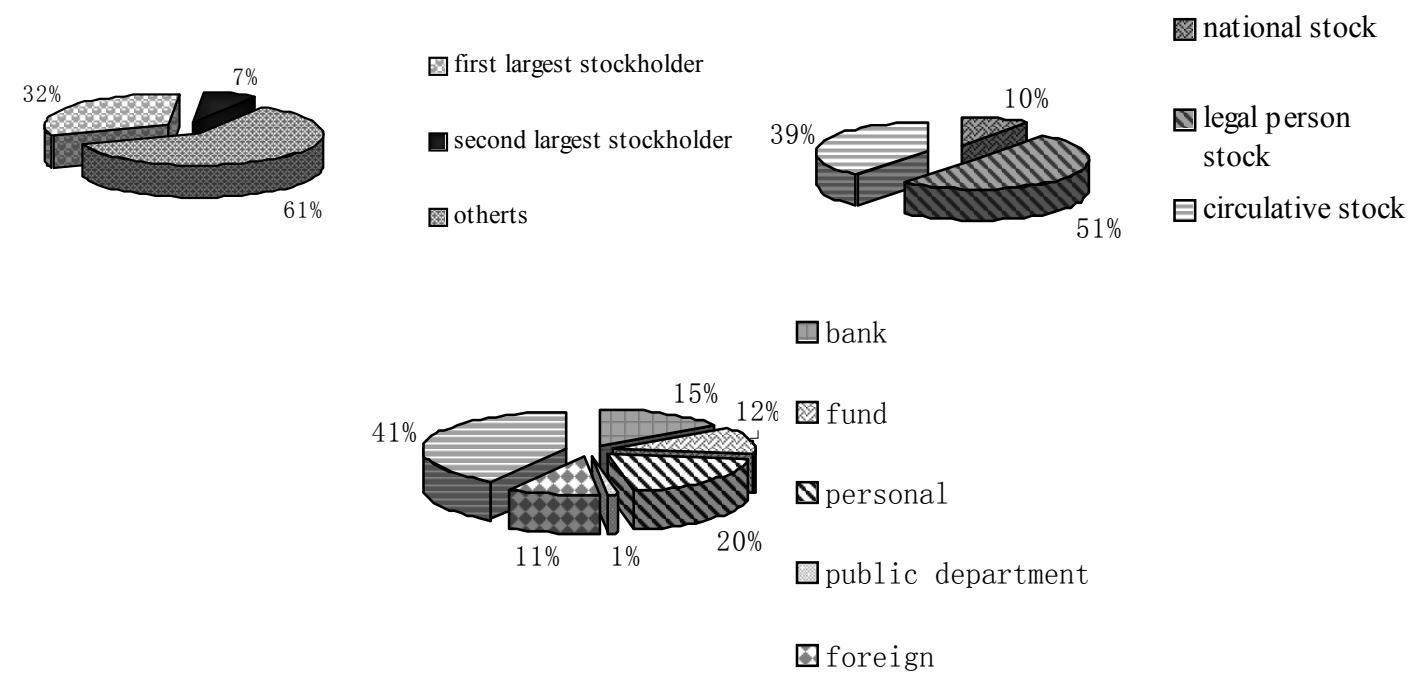

Figure 3. Ownership Structures in Japan

\section{Improper incentive mechanisms is the direct cause that creates the distorted accounting information}

The problem of incentive mechanism is very significant in corporate governance. Because ownership and managerial authority are separate in modern company. The interest of the stockholder and the managerial authority has diverged. For this reason, owners design incentive mechanism to make the action of managerial authority agree with stockholder's benefit. In the U.S. the incentive mechanism of the public company was most obvious. By the end of $2001,90 \%$ of the great business of the U.S. sent non-qualified stock options to managers, $60 \%$ of the revenue of managers came from stock. Yet incentive mechanism is "two blade swords". On one hang it makes managers work efficiently, but on the other hand it motivates managers to supply the distorted accounting information. Swindles which happened in the U.S. confirm that the action of giving excessive motivation to inspire managers just like "drinking poison to quench thirst". The benefits of managers should not be combined together with company benefit. This is the cause of the distorted accounting information. To some degree, non-qualified stock options are the main reason of the American accounting swindles law cases. We consider that improper incentive mechanism is the direct cause that 
creates the distorted accounting information.

The American accounting swindle law case originated from over compensation, but the reason for distorted accounting information of the public company in China is just short of essential incentive mechanism. Nowadays, the revenue form in China is comparatively simple (Tab. 1). Monthly pay and bonus are the most common form that the companies adopt. There is an intimate relationship between bonus and accounting benefit, so in the case of insider control, use bonus as incentive means usually leads the publish distorted accounting information to control benefit. On the other hand, the traditional viewpoint of Chinese is "The government official is most important". Some managers' goal is to become an official or politician, so for those people accounting becomes a chess piece. It is not strange for a company to appear to "turn hostile suddenly". Though analysis of those financial malpractice cases, we may discover that the improper incentive mechanism impels managers to control the profit, thereby cause the distorted accounting information.

Table 1. Corporation administration person year revenue together revenue shape

\begin{tabular}{lllll}
\hline Item & Under10000 & $10000-20000$ & $20000-50000$ & Over50000 \\
\hline Monthly pay & 90.6 & 85.2 & 76.5 & 64.7 \\
Yearly pay & 5.6 & 12.2 & 20.4 & 26.2 \\
Mortgaged & 6.7 & 4.4 & 8.8 & 4.4 \\
Dividend & 6.7 & 9.3 & 13.2 & 24.2 \\
Others & 2.9 & 2.2 & 2.1 & 6.0 \\
\hline
\end{tabular}

4. The unqualified supervisory mechanism is the external cause that creates the distorted accounting information

The supervisory mechanism of public company consists of exterior supervision and interior supervision. Exterior supervision means the company restricts the managers' action through outside marketplace. These marketplaces chiefly are the product marketplace, the manager marketplace, and the capital marketplace. Interior supervision means that companies restrict the managers' action through specific system design. Exterior supervision will take a long time to be established, and tradition, culture, political of environment will have a great affect on it. Hence it is a long period of time for exterior supervision to resolve the distorted accounting information, and it cannot accomplish it in one move. Under this situation, resolving the problem as quickly as possible will depend on interior supervision. The way of the U.S. is worth studying. After experiencing a series of accountancy scandal cases, the U.S. Government passed Sarbanes---Oxsley Action of 2002 to resolve accounting information quality. The law had several aspects, while are as follow:

(1) The act also has stiffened penalties for corporate and criminal fraud by company insiders. The law makes it a crime to destroy, alter or falsify records in a federal investigation or if a company declares bankruptcy. The penalty for those found guilty includes fines, or up to 20 years imprisonment, or both.

(2) No personal loans or extensions of credit to company executives either directly or though a subsidiary, except for certain extension of credit under an open -ended credit plan or charge card, home improvement and manufactured home loans, or extensions of credit plan by a broker or dealer to its employee to buy, trade or carry securities.

(3) Any CEO or CFO who "recklessly" violates his or her certification of the company financial statement. If "willfully" violates, fine of up to $\$ 1,000,000$ and /or up to 10 years imprisonment. Fine of up to $\$ 5$ million and /up to 20 years imprisonment.

(4) The act vests the audit committee of a publicly traded company with responsibility for the appointment, compensation and oversight of any registered public accounting information to perform audit services.

The supervisory mechanism of the public company in China consists of stockholder board, corporate board and supervisor board. But those boards cannot supervise the manager efficiently. When the outstanding achievement is not very good, certainly the manager will utilize different measures and announce the distorted accounting information to attain individual and political aims.

\section{Pattern of the relationship between the corporate governance and the distorted accounting information and some proposals}

Accounting information is orient to advance efficiency and improve performance of company though using the mechanism to control the accountant datum. If this corporate mechanism brings into play efficiently, the accounting information must combine well with capital market. Because the price of stock can identify effort of manager and the possibility of controlling the surplus, the accounting index may sieve the unconventional influence of non-economic factors. The other way round, the corporate governance can promote the manager to report true accounting information. The relationship can be described by Figure 4. 


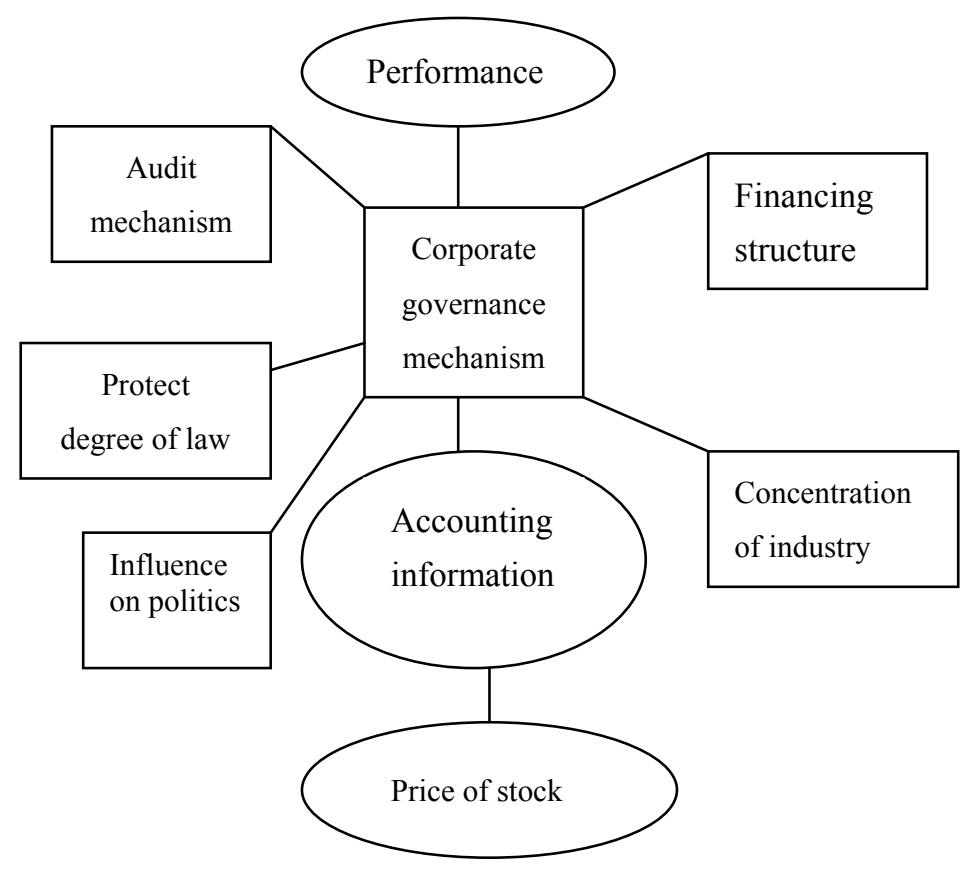

Figue 4. Relationship of Accounting Information and the Corporate Governance

After the accounting information is announced by the manager, through the stockholder board $\backslash$ the corporate board and the supervisor board, it finally becomes the public record. By means of the analysis of the foregoing paragraphs, we think the main elements affecting quality accounting information are the ownership structure, the supervisory mechanism and the incentive mechanism. According to the formula below, the real accounting information is measured to A, the improperly ownership structure, supervisory mechanism and incentive mechanism which affect the degree of the accounting information quality is $\alpha, \beta, \gamma$, the credible accounting information is $\mathrm{Y}$ :

$Y=A[1-\alpha][1-\beta][1-\gamma]$

$(0 \leq \alpha \leq 1,0 \leq \beta \leq 1,0 \leq \lambda \leq 1$, just $\gamma \leq \alpha, \beta)$

To be fit for Chinese the conditions; solving problem of the distorted accounting information involves changing ownership structure, and establishing incentive mechanism. Moreover this process involves improving the setup of interior and exterior supervisory mechanism.

The following steps may be taken in the process:

(1) Reducing the proportion of the national stock and personal stock in the specified situation, and then adding to the proportion of circulation stock.

(2) Improving the essential system makes the valid demand accounting information a priority.

(3) Improving the standard achievement evaluation target and the personal payment system, relieving the need to announce the distorted accounting information.

(4) Establishing more kinds of incentive mechanism.

(5) Speeding up product market,director man and capital market establishment.

(6) Establishing improved stockholder statute for their protection.

(7) Establishing the independent audit commission, with strange built-in control.

(8) Improving the supervisor board system.

\section{Conclusions}

The distorted accounting information possesses two general direction financial report malpractice and profit control. The scope of the study is restricted to the relationship between the financial report malpractice and corporate governance. As to the corporate government, the study only carries on preliminary research through three main respects. The study proposes the easy mathematical model of the accounting information quality. That the relationship between the supervisory of the exterior, statue, the intermediary organization and the distorted accounting information is still awaiting further research. 


\section{References}

Averch, Harvey and Johnson, Leland. (1963). Behavior of the Firm under Regulation Constraint, American Economic Review. 52, 1053-69.

Chen Guohui \& Lu Jianqiao. (1996). Structures of Enterprises' Property, Quality of Accounting Information and Accounting Supervision, Accounting Research. 5, 33-37.

Chen Guohui and Li Changqun. (2000). On Distortion of Accounting Market and Governance Supervision, Accounting Research. 8, 24-28

Ge Jiashu, the Analysis of Economic Background of Enron Incident. (2003). Accounting Research, 1, pp9-14.

Wu Shuipeng. (2000). Modern Enterprise System and Accounting Supervision, Finance and Accounting. 3, pp23-25. 